\title{
Perceptions of clients regarding family planning service delivery in a clinic of the Greater Johannesburg Metropolitan Council
}

\author{
A Kellner, MCur \\ Department of Nursing, University of Johannesburg
}

K Jooste

Professor, Department of Nursing, University of Johannesburg

W Jacobs

Lecturer, Department of Nursing, University of Johannesburg

\section{Kev words}

Women, reproductive age, family planning

\section{Correspondence address \\ Prof K Jooste \\ Department of Nursing \\ University of Johannesburg \\ Auckland Park, 2006}

Tel :(011) 559-2857

E-mail : kjooste@uj.ac.za

\begin{abstract}
Curationis $33(2): 13-24$
Unwanted pregnancies with their negative impact on both women and children occur on an ongoing basis in Gauteng, South Africa. One way to prevent unwanted pregnancies is to use a reliable contraceptive method available free of charge from primary health care clinics providing family planning services throughout Gauteng Province. A literature review was completed on women and access to family planning services and an interview schedule (questionnaire) was developed. The purpose of this study was to describe guidelines to meet the expectations of clients accessing family planning services provided by a clinic in Region F, Area 28 of the Greater Johannesburg metropolitan council. This quantitative, exploratory, descriptive and comparative study measured the gaps between the expectations of participants on service delivery and the extent to which these expectations were met. A convenience sample was conducted and consisted of 50 women of reproductive age (ages 15 to 49) attending the family planning clinic. Pre-testing of the instrument was conducted. Structured interviews with a interview schedule were conducted before and after women attended a family planning service. Inferential statistics indicated that there was a significant gap between the client expectations of family planning service delivery and the extent to which these expectations were met. Of the sixty-four items where women indicated the extent of their expectations the findings on only three items were not statistically significant. These gaps were addressed by proposing managerial guidelines to be implemented by the nurse manager in charge of the facility, on which this article will focus. Validity and reliability principles were ensured in the study. Ethical principles were adhered to during the research process.
\end{abstract}




\section{Introduction}

Family planning service delivery is of the utmost importance in the current health care scenario of unintended pregnancies (Health Systems Trust, 2002:1; Health Systems Trust, 2007:1). Seventy-five million unintended pregnancies occur world-wide every year, mostly because of couples not using contraception(WHO, 2000a:6). Women of reproductive age in Gauteng, who are using or whose partners are using contraceptive methods are calculated at $60.9 \%$. The high percentage of couples (nearly $40 \%$ ) not using contraceptives leads to a large number of unintended pregnancies (Medical Research Council, 2001:1). A woman's ability to space and limit the number of her pregnancies has a direct impact on her health and well-being, as well as on the outcome of her pregnancy (Braam, 2002:14-15; Kirby, 2006:54; Venugopal \& Upadhyay, 2002:2). The role of the family planning service becomes apparent when clients have certain expectations that should be met. Ehlers, Maja, Sellers and Gololo (2000:43-44) state that the way in which family planning services are delivered becomes a major obstacle to their use. The number of unplanned/unintended pregnancies could bear witness to this fact. Improving family planning service delivery in line with clients' expectations is essential to putting clients first. Services should be provided to meet health care standards and to treat clients as they want to be treated. Clients' concerns and preferences are valid and important (Kols \& Sherman, 1998:9-10). A key area for improving family planning service delivery identified by the WHO is assessing and understanding the behaviour and perceptions of the clients of family planning and other reproductive health services (WHO:2000b:1).

Although investigation of clients' expectations of health care was previously undertaken in South Africa, it was not focussed on family planning in the Johannesburg Metropolitan area (Ehlers, et al, 2000:43). In the fight against unintended pregnancies and its consequences and in keeping with international trends it is thus considered important to take the client's expectations of service into consideration when attempting to address the issue of family planning services provided.
It is clear that, without consulting the client, bridging the gap between what clients expect and the actual service received by clients can't be planned for.

\section{Literature review}

According to the Department of National Health, the IPPF and the WHO family planning service delivery comprises seven fundamental elements for measuring the care that will serve as the theoretical departure of this study (DOH, 2000:22-31; WHO:2000b:1).

Access to family planning is recognised as a right of all individuals and couples (Powlson, 2004:12; University of Saskatchewan, 2008:1). Client expectations start with accessibility of services, implying that services should be affordable and conveniently situated (JHPIEGO, 1998a:4; WHO, 2003:1). In a family planning clinic nurses' behaviour with regards to the appropriateness and acceptability of services they provide falls into the domain of ethics (Smit \& Cronje, 2002:490-491). Appropriateness and acceptability of services implies that services are designed with the needs of the client in mind, rather than that of the staff. Services should be clean and inviting to clients and should not pose a health risk for clients accessing the service. Waiting times should be acceptable to the clients visiting the clinic (FHI, 2004:2). Accurate, scientifically sound, complete and adequate information has to be made available to the client so that she can make the best choice for herself. The nurse giving the information should be technically competent (RHRU, 2000:27). Information shared with clients includes information for making informed decisions, information needed for the client to use her method correctly and safely.

Sub-optimal interpersonal interactions between family planning nurses and clients are seen as a barrier to family planning access (WHO, 2008:1). Clients who are welcomed, treated with respect and encouraged to ask questions and participate in their health care are more likely to be satisfied contraceptive users. Nurses should change their behaviour in the way they initiate a consultation (Metcalf, 2004:42). Clients have the right to decide freely which method to use and should receive the method of choice unless contra-indicated (Powlson, 2004:13). Choice is one of the components necessary for quality of care in the framework suggested by Family Health International (FHI, 2004:2). The South African Department of Health has set it as a goal to 'expand and strengthen the current method mix to meet varying needs (DOH, 2000:27). Ensuring the availability of a wide choice of methods promotes client-centred care where the client receives a method she wants to use without compromising her health (Jarvis, 2005:255).

The prevention and treatment of Sexually Transmitted infections (STIs), including HIV and AIDS is essential. When a client suspects that an infection may be present she should seek help as soon as possible (WHO, 2005:48). Where clients are exposed to the risk of STIs, HIV and unintended pregnancy, a sexual risk-reduction intervention is recommended, that includes abstinence and emphasises social skills, such as communication and condom use, (Champion, Shain \& Piper, 2004:294).

Three mechanisms of continuity of care are important, namely follow-up contraceptive and reproductive health care, the need for clients to know when to return for services and access to a service when needed (FHI, 2004:2). The Department of National Health in South Africa focuses on the importance of discussing with clients that they may come in to the clinic when problems arise or questions need to be answered (DOH, 2004:19). Record keeping should be of such a nature that the next provider is aware of decisions made during previous visits and of the areas of concern that should be followed up (Guillebaud, 1993:398,441-448; Hatcher, Rinehart, Blackburn, Geller \& Shelton, 2001:vi).

\section{Problem statement}

Uninformed women are subject to misconceptions and misinformation regarding family planning and contraception, which could lead to women discontinuing the use of the available free services. Their expectations of service delivery aren't met and by not using family planning services they fall victim to unintended pregnancies. This 
results in high maternal mortality and morbidity rates and unacceptably high teenage pregnancy rates, and has a direct impact on women's health and wellbeing as well as the outcome of their pregnancies (Medical Research Council, 2001:1; Ehlers, et al, 2000:43-44; WHO: 2000b:1). The following research question applies: "To what extent do the family planning services delivered by a clinic in Region F, Area 28 in the Greater Johannesburg Metropolitan Council in Gauteng meet the expectations of its clients?"

\section{Objectives of the study}

The objectives of the study were to:

- explore and describe the gap between clients' expectations before and after family planning services have been delivered in a clinic in Region F, Area 28 of the Greater Johannesburg Metropolitan Council;

- describe guidelines for nursing managers regarding family planning service delivery in a clinic in Region F, Area 28 of the Greater Johannesburg Metropolitan Council.

\section{Definition of key concepts}

\section{Client}

According to the Medical Research Council (MRC) women of reproductive age include women aged fifteen (15) to forty-nine (49) years. For the purposes of this study the participant is a female client of reproductive age who approaches the health care system for family planning services (DOH, 2001:1; Medical Research Council, 2001:1).

\section{Family planning}

According to the Department of Health, family planning is the ability of couples to decide on and attain their desired number of children and the desired spacing between births. Family planning services incorporate the provision of information regarding diagnosis and management of STIs, including HIV and AIDS (DOH, 2000:33).

\section{Guidelines}

For the purpose of this study guidelines refer to directives that will assist the nurse manager of the clinic to meet the expectations of family planning service delivery of clients receiving family planning services at a clinic in Region F, Area 28 of the Greater Johan- nesburg Metropolitan Council (Soanes, Spooner \& Hawker, 2001:398).

\section{Research design and sample}

A quantitative, exploratory, descriptive and comparative design was followed. The accessible population consisted of women of reproductive age (ages 15 to 49 years), receiving family planning services at a clinic in Region F, Area 28 of the Greater Johannesburg Metropolitan Council (DOH, 2001:1). A convenience sample of 50 women of reproductive age, (ages fifteen to forty-nine) receiving family planning services at a clinic in region F of the Greater Johannesburg Metropolitan Health Department was selected in the study. This provided a means of obtaining information in un-explored areas (Burns \& Grove, 1993:239-247). Clients coming for both first visits and repeat visits in a particular month were selected when they accessed the family planning service.

\section{Data gathering}

Data were gathered in two phases. An interview schedule (structured questionnaire) and the recording of field notes were undertaken during a person-to-person interview. A similar 4point scale instrument was completed before and after the client/participant received family planning services. This interview schedule included structured items on the seven elements of family planning service delivery and a few open ended questions (De Vos, 1998:297; Babbie \& Mouton, 2001:249256).

\section{Data analysis}

Data generated by data gathering of a numerical nature were analysed with descriptive statistics. Descriptive statistics allow the researcher to find meaning in what is seen, promote insight and also to investigate a phenomenon to facilitate better insight (Burns \& Grove, 2005:527). Inferential statistics such as parametric tests (one sample t-test) and non-parametric tests such as Marginal Homogeneity (MH) testing were used to analyse data which were gathered through the structured interview schedules (questionnaires). Participants' expectations of family planning service delivery and the extent, to which these expectations were met, were analysed using single-sample ttest. The t-test was used to determine the disparities/gap between clients' expectations of family planning service delivery with the established norm of 4 . The p-values which resulted from the t-test represented the probability of error in accepting our explanation for the existence of a gap (Table 1).

An individual gap was measured on each item using a Marginal Homogeneity test. Each item's value was compared to the overall p-value for each section as displayed in Table 2 . Where the $\mathrm{MH}$ - test on an individual item was less than the p-value displayed (Table 2 ), the gap was considered meaningful. By using the MH-test significant differences were found between clients' expectations of service delivery and the extent to which the clients' expectations of service delivery were met, in 61 out of 64 items.

\section{Validity and reliability}

Validity deals with the extent to which the instrument measures that which it is intended to measure. Certain principles had to be applied in order to ensure validity (Babbie \& Mouton, 2001:122; Burns \& Grove, 1993:342-347). Validity was ensured by using the same interview schedule for all participants. All categories in the interview schedule were standard for all interview schedules. The use of a standard interview schedule and training of a research assistant ensured that the researcher stayed in control of the content and purpose of the interview (Parahoo, 1997:297). The reliability of an instrument deals with the ability of an instrument to produce the same results over a period of time when used with the same participants in terms of stability, equivalence and homogeneity (Burns \& Grove, 2005:374). The structured interview instrument was given to experts in the field of the study as well as statisticians for scrutiny in the pre-testing of the instrument. Participants were made aware of the time involved for the interview process, and had agreed to be interviewed with the knowledge of how long the interview would take eliminating urgency within the client to finish the interview. The same structured interview schedule was used throughout the study. 


\begin{tabular}{|c|c|c|c|c|c|c|}
\hline & \multicolumn{6}{|c|}{ Test Value $=\mathbf{4 . 0 0}$} \\
\hline & \multirow[b]{2}{*}{$\mathrm{t}$} & \multirow[b]{2}{*}{ Df } & \multirow[b]{2}{*}{ Sig. (2-tailed) } & \multirow[b]{2}{*}{$\begin{array}{l}\text { Mean Differ- } \\
\text { ence }\end{array}$} & \multicolumn{2}{|c|}{$\begin{array}{l}95 \% \text { Confidence Interval of } \\
\text { the Difference }\end{array}$} \\
\hline & & & & & Lower & Upper \\
\hline blmean.after & -6.22 & & 0.0 & -0.69333 & -0.9172 & -0.4695 \\
\hline b2mean.after & -7.58 & & 0.0 & -0.61308 & -0.7756 & -0.4506 \\
\hline b3mean.after & -16.08 & & 0.0 & -1.05273 & -1.1843 & -0.9212 \\
\hline b4mean.after & -5.91 & & 0.0 & -0.52200 & -0.6992 & -0.3448 \\
\hline b5mean.after & -7.44 & & 0.0 & -0.58571 & -0.7438 & -0.4277 \\
\hline b6mean.after & -14.56 & & 0.0 & -1.06000 & -1.2063 & -0.9137 \\
\hline b7mean.after & -6.13 & & 0.0 & -0.53500 & -0.7102 & -0.3598 \\
\hline
\end{tabular}

\section{Ethical considerations}

Ethical clearance for the study was granted by the ethical committee of the Faculty of Health Sciences of the University of Johannesburg. Consent to undertake the research was granted by both the Gauteng Department of Health and the Greater Johannesburg Metropolitan Council. Clients could decide whether they wanted to volunteer their time and information to participate in research. The participant had the right to withdraw from or terminate participation in the study at any stage of the process. Informed consent was obtained from all participants. The right of privacy of all participants was further adhered to by conducting the structured interview away from other people in the clinic, in a room with a door that was closed (Burns \& Grove, $2005: 186)$. The researcher took steps to ensure to the right of anonymity of all participants. No information linking a participant to a specific form was permitted (Burns \& Grove, 2005:188). The original data collection instruments have been locked away (Burns \& Grove, 2005:188).

\section{Discussion on results}

\section{Demographic profile of} participants

Fifty women of reproductive age completed Section 1 of the interview schedule. The ages of participants were well distributed between the ages of fifteen to forty-nine years with three $(6 \%)$, of the participants aged between fifteen and nineteen years 45 participants $(n=45,90 \%) 20$ to 44 and two (4\%) participants, 45 to 49 . A larger number, 34 $(68 \%)$ of the $50(100 \%)$ participants in the study were unmarried $(68 \%)$ compared to sixteen (32\%) participants who were married. Eighteen (36\%) participants were employed. Just over two thirds $32(64.0 \%)$ of the participants were unemployed. The findings that the majority of participants were unemployed and unmarried, could indicate that they are of a low income group. Almost three quarters of the participants $(n=36,72 \%)$ have had two to three pregnancies. Eight (16\%) participants have had four or more pregnancies. Only six (12\%) participants have had one pregnancy. In response to the question whether participants have visited a family planning clinic before; only seven participants (14\%) had never visited a family planning clinic before. From a participant's perception, the majority $(86 \%)$ reported that they have visited a family planning clinic in the past.

Table 3 outlines that significant differences (gaps) were found on most of the responses between participants' expectations of the family planning service delivery and the extent to which expectations in this regard were met.

\section{Accessibility and availability of}

\section{family planning services}

The time management of a family planning service(s) is a key aspect of accessibility of the service. The ease with which clients are able to utilise the family planning service is compromised when clinic hours are not convenient to the proportion of the community who may have benefited from the service (Powlson(Ed), 2004:2). Access is, furthermore, compromised where nurses are not available as scheduled, or clients are turned away without counselling or care (FHI, 2004:2). Participants could have heard about the location of the clinic by word of mouth, which was reflected in the comment of a participant (and recorded in the field notes); " $A$ friend of mine came here and told me exactly what to look out for to find the clinic."

\section{Appropriateness and acceptability of services to the client}

When the appropriateness and acceptability of services are considered, it means that services should be designed with the needs of the client in mind rather than that of the staff. Issues such as the privacy and respect for the client's dignity are addressed. The clinic environments should be made inviting and waiting times should be acceptable to the clients visiting the clinic (FHI, 2004:2). Ethical measures of privacy and respect should be important to clients. Past research has 


\begin{tabular}{|l|l|}
\hline Section & p-vahe \\
\hline 1. Accessibility and availability of family planning service & 0.01667 \\
2. Appropriateness and acceptability of services to the client & 0.00385 \\
3. Information about available family planning services and contraceptive methods & 0.00455 \\
4. The interpersonal skills demonstrated by the nurse & 0.0025 \\
5. The choice of contraceptive methods made available & 0.00714 \\
6. Prevention and care of Sexually Transmitted Infections (STIs) including HIV & 0.00833 \\
7. Mechanisms that ensure follow-up care and continuity of care & 0.0125 \\
\hline
\end{tabular}

brought to light that clients feel that not being seen or heard by other than their nurse during a consultation shows respect towards them. Not being respected in this fashion leads to dissatisfaction with the service (Ramchandran, 2007:13). A participant justified the lack of privacy when undressing, by making the following comment (field note): "Perhaps we should just get used to it. After all, we are all women." Ethical measures of comfort should be taken into consideration. When planning the provision of family planning services the comfort of the client should always be kept in mind. This starts with the client's experience when walking into the clinic waiting area and extends through to the examination bed that the client is examined on. Clients view it as a sign of respect when a service is provided with their comfort in mind (Powlson(ed), 2004:16). Safety measures in terms of environmental risk management should be adhered to. Measures in terms of environmental risk management that ensure a healthy and safe environment, to ensure clients' physical and mental wellbeing, is a patient's right ( $\mathrm{DOH}$, 2000:18).

\section{Information about available family planning services and contraceptive methods}

Research has produced a vast body of information which has the potential to assist the client in making meaningful decisions about which contraceptive to use, how to use it so that they will enjoy the full benefit of the method's protection and how to use it safely without harming their health. Good patient education is a key to effective contraception (Anon, 2005: 51).

Information management in terms of information is needed for the client to make an informed method choice. In order for a client to make an informed choice, the latest information about available contraceptive methods should be made available. This is essential for participative decision making (Rudy, Tabbutt-Henry, Schaefer \& Mc Quade, 2003:2). Participants mentioned a shortfall in receiving information about the contraceptive method's mode of action and felt the clinic was too busy for nurses to take the time to educate the clients; the field notes outline the following comment of a participant: "No, they do not do this. I think the clinic gets too busy and the line must move. They do not have time to do this." Information management in terms of information to use her method correctly. Full instructions should be given to clients on how to use a method consistently and correctly at home as this is crucial to the success of the method and promotes compliance (WHO, 2004b:3; RHRU, 2005:31, 55-57 \& Lete, 2006:14). Two items referred to information needed by the client for the correct use of her method, namely, demonstrating the use of the client's method of choice to her and being given written information about her chosen contraceptive method.

\section{Interpersonal skills demonstrated by the nurse}

The nurse should demonstrate good interpersonal skills when assisting the client. In the family planning setting it is important for accurate, scientifically sound, complete, and adequate information to be made available to the client in a way that will be understandable to them. Then the client will be able to make an informed choice and use that method optimally and safely
(RHRU, 2000a 2). Interpersonal skills in terms of professional behaviour are needed. The tone must be set when the client has her first contact with the nurse in the clinic (WHO, 2005:48). The client must be made to feel welcome in the consultation room (FHI, 1998:2). The client should feel that she is the most important person in the room and that she is respected as a person in the way she is addressed. Interaction, by the nurse in a non-professional manner, together with an attitude that shows disinterest in the client is found to be a barrier to accessing services (Lester \& Allan, 2005: 7).

Interpersonal skills in terms of consideration of cultural diversity are important. The spoken language of the client should be determined by the nurse. Then steps should be taken to ensure that the client receives information essential for her choice of method and the optimal use of this contraceptive method. This information should be in a language and vocabulary at a level which the client can understand the nurse (Coetzee \& Moys, 1999:44). The nurse should gain insight in the client's situation. It is important for the nurse to portray herself as understanding and empathetic. Clients' value individualised service and prefer providers who have made the effort to understand their particular health care situation and need for service delivery (JHPIEGO, 1998b:1; RHRU, 2000b: 10, 27). One client highlighted a particular problem she encountered in the process of trying to access a service as a foreigner: "I' $m$ from the Congo. I came to South Africa in the eighties and was treated very well. Now when they ask why I as an African speak English, they say it is because I'm an alien. Their tone of voice changes and they are not 
friendly anymore. They say I must go back where I came from."

Interpersonal respect referred to the nurse showing the client interpersonal respect and fulfilling their expectation on service delivery in this regard. Participative decision making is an important principle in delivering family planning services. Client participation improves the outcome of the interaction and should, therefore, be encouraged (FHI, 2004:2). Success of contraceptive use will be achieved when the client takes ownership of her own decisions (Egan, 1998:48; De Freitas, 2007:180).

\section{The choice of contraceptive methods made available}

Clients should have a choice of contraceptive methods in family planning services. Choice is one of the components necessary for quality of care in the framework suggested by Family Health International (FHI,2004:2). A broad range of methods has made services more accessible (WHO, 2008:1). For clients to be able to choose a method that suits their circumstances, programmes need to make as many methods as possible available for the client to choose from (WHO, 2004a:1).

Nurses should facilitate the process of participative decision making. Services will have been made more accessible by a broad range of contraceptive methods being held in stock (WHO, 2008:1). For clients to be able to choose a method that suits their circumstances, a well-run programme will ensure that many contraceptive methods are made available for the client from which a choice can be made (WHO, 2004a:1). Client-centred care is essential. Clients should be given their method of choice unless contra-indicated as this leads to greater satisfaction, with a successful use of a contraceptive method (Powlson (ed), 2004:13).

\section{Prevention and care of sexually transmitted infections including HIV}

Family planning services are becoming increasingly integrated with other services, especially in addressing STIs (including HIV and AIDS) (Rudy et al, 2003:2; DOH, 2004a:22-31).

Diagnosis and treatment of STI's are needed. Screening as well as treatment according to syndromic management guidelines should be provided by all nurses providing a family planning service (Dickson et al, 2005:28; WHO, 2005:1). Nurses do not appear to routinely assess for the presence of STIs which is apparent with this comment from the field notes: "It is not easy to tell someone about this. No-one has asked me about this. I have never thought about it, you know, but it is important, very important. They should be asking". Risk reduction should be a focus area. Clients should be informed and helped to understand the risks that expose them to infection with STIs and HIV, and be able to protect themselves. Recommendations have been made that up to date information about STIs should be combined with other sexual health services (Lester \& Allan, 2004:3). The nurse should inform family planning clients about HIV and Aids, since all family planning clients are considered to be sexually active and, therefore, at risk to some extent of becoming infected with HIV (DOH, 2000:21, 23, 25, 28 \& 36; Evian, 2000:4-7).

\section{Mechanisms that ensure follow- up and continuity of care of women of reproductive age}

Continuity of care is considered to be essential for the continued successful use of a contraceptive method. Clients should be given information on when to return to the clinic for services and to have access to a service when needed (FHI, 2004:2). Clients should be told to return when experiencing sideeffects and complications, or when to return for follow-up visit in time to receive the next supply of contraceptives (FHI, 2004:2). Continuous reliable supplies being available in stock are essential for ensuring continuity of care. It is considered the client's right to receive contraceptive supplies for as long as she wants (Powlson (ed), 2004: 1618). All barriers should be removed that will prevent the continued use of contraception. Where service delivery has been streamlined in providing a client with a re-supply of contraceptives; clients are more likely to continue using their method over the long term; preventing unintended pregnancies (Ramchandran, 2007:2). Family planning services should be provided in a well-managed system with clear referral pathways so that health problems detected by the nurse that fall out of her scope of practice may be dealt with (DOH, 2000:19\& 29).

\section{Guidelines}

Guidelines can be implemented to effectively deliver family planning services to women of reproductive age in a clinic in Region F, Area 28 of the Greater Johannesburg Metropolitan Council. Possible managerial actions that could be taken are by no means limited to the description below.

Guideline 1: The family planning clinic should be made accessible and available to women of reproductive age through time management and visibility.

The findings show that a statistically significant gap exists between clients' expectations of the accessibility and availability of the family planning clinic to women of reproductive age and the extent to which these expectations are met. Access to and availability of family planning services are/is considered a right of the client (DOH, 2001b:11). The nursing manager should address the daily opening times of the family planning service and the availability of nurses during advertised hours of the family planning service.

\section{Guideline 2: Family planning service provision should be appropriate and acceptable to women of reproductive age taking into account ethical principles and a safe environment.}

Appropriateness and acceptability of services means that services are designed with the needs of the client in mind, rather than that of the staff. Clients have a right to privacy and respect as well as a safe, healthy environment, (DOH, 2001b:13, 23). The manager should ensure that services delivered meet the highest possible ethical standards (DOH, 2001b:10). The client should be respected and be allowed to undress in privacy. Ethical measures ensure that the client's right to have her privacy and dignity respected are implemented (Powlson, 2004:16).

\section{Guideline 3: Information about family planning services and}




\section{Significant differences on perceptions regarding family planning services}

\begin{tabular}{|c|c|c|c|}
\hline & GAPS & SPECIFICASPECTS & $\begin{array}{c}\text { IIEM } \\
\text { NR }\end{array}$ \\
\hline \multirow[t]{2}{*}{$\begin{array}{l}\text { and availability } \\
\text { ning service. }\end{array}$} & Time management & $\begin{array}{l}\text { The clinic is open at times that suit the client. } \\
\text { Nurses are available during advertised hours. }\end{array}$ & $\begin{array}{l}1.1 \\
1.3\end{array}$ \\
\hline & Visibility of the clinic & The clinic is clearly marked on the outside. & 1.2 \\
\hline \multirow[t]{3}{*}{$\begin{array}{l}\text { ness and ac- } \\
\text { services to the }\end{array}$} & Ethical measures of privacy and respect & $\begin{array}{l}\text { The nurse allows the client to undress in privacy. } \\
\text { The client isn't unnecessarily exposed during the examination. } \\
\text { The client is examined in a way that respects her dignity. } \\
\text { No-one can see what the nurse is doing with the client. } \\
\text { The nurse respects the client's privacy (auditory privacy). } \\
\text { No-one walks in and out of the room. }\end{array}$ & $\begin{array}{l}2.1 \\
2.2 \\
2.3 \\
2.5 \\
2.6 \\
2.7\end{array}$ \\
\hline & Ethical measures of comfort & $\begin{array}{l}\text { The bed the client is examined on is comfortable. } \\
\text { There are enough chairs for everyone to sit in the waiting area. } \\
\text { There is enough light in the waiting area to be able to read. }\end{array}$ & $\begin{array}{c}2.4 \\
2.9 \\
2.10\end{array}$ \\
\hline & Environmental safety & $\begin{array}{l}\text { The waiting area is clean. } \\
\text { The waiting area is not smelly. } \\
\text { There are clean toilet facilities available. } \\
\text { The nurse's consultation/examination room is clean. }\end{array}$ & $\begin{array}{l}2.8 \\
2.11 \\
2.12 \\
2.13\end{array}$ \\
\hline \multirow[t]{2}{*}{$\begin{array}{l}\text { bout available } \\
\text { ag services and } \\
\text { methods }\end{array}$} & $\begin{array}{l}\text { Information management in terms of infor- } \\
\text { mation needed for the client to make an } \\
\text { informed method choice. }\end{array}$ & $\begin{array}{l}\text { The client is told about different contraceptive methods in stock. } \\
\text { The client is informed of her method compared to other methods. } \\
\text { The biological process of the client's method is explained. } \\
\text { The client is told about the benefits of using her method of choice. } \\
\text { The client is told about common side-effects of method of choice } \\
\text { The client is told about falling pregnant after stopping her method. }\end{array}$ & $\begin{array}{l}3.1 \\
3.2 \\
3.3 \\
3.4 \\
3.5 \\
3.8\end{array}$ \\
\hline & $\begin{array}{l}\text { Information needed for the client to use } \\
\text { her method correctly }\end{array}$ & $\begin{array}{l}\text { The nurse demonstrates the use of the client's method of choice. } \\
\text { The client is given written information about her chosen method. }\end{array}$ & $\begin{array}{l}3.7 \\
3.11\end{array}$ \\
\hline
\end{tabular}




\begin{tabular}{|c|c|c|c|}
\hline & GAPS & SPECIFIC ASPECTS & $\begin{array}{l}\text { IEM } \\
\text { NR }\end{array}$ \\
\hline & $\begin{array}{l}\text { Information management in terms of infor- } \\
\text { mation needed for the client to use her } \\
\text { method of choice safely }\end{array}$ & $\begin{array}{l}\text { The client is told about possible health risks of using methods. } \\
\text { The client is told about the unique protection offered by con- } \\
\text { doms. } \\
\text { The client is told why vital signs have to be monitored. }\end{array}$ & $\begin{array}{l}3.6 \\
3.9 \\
3.10\end{array}$ \\
\hline $\begin{array}{l}\text { al skills dem- } \\
\text { e nurse }\end{array}$ & $\begin{array}{l}\text { Interpersonal skills in terms of professional } \\
\text { behaviour }\end{array}$ & $\begin{array}{l}\text { The nurse greets the client using her formal title } \\
\text { The nurse introduces herself using her formal title. } \\
\text { The nurse speaks to the client in a way that shows good man- } \\
\text { ners. } \\
\text { The nurse's facial expression makes the client feel comfortable. }\end{array}$ & $\begin{array}{c}4.1 \\
4.2 \\
4.6 .5 \\
4.6 .6\end{array}$ \\
\hline & $\begin{array}{l}\text { Interpersonal skills in terms of considera- } \\
\text { tion of cultural diversity }\end{array}$ & $\begin{array}{l}\text { The client is spoken to in a language she can understand. } \\
\text { The nurse uses words that the client can understand. }\end{array}$ & $\begin{array}{l}4.3 \\
4.4\end{array}$ \\
\hline & Gaining insight in the client's situation & $\begin{array}{l}\text { Repeating the information the client told the nurse about her } \\
\text { situation in such a way that it shows that the nurse has under- } \\
\text { stood. } \\
\text { Considering the client's cultural beliefs. } \\
\text { Repeating all the client's felt needs as she explained them. } \\
\text { Repeating the client's point of view about a method. }\end{array}$ & $\begin{array}{l}4.5 .1 \\
4.5 .2 \\
4.5 .3 \\
4.5 .4\end{array}$ \\
\hline & Interpersonal respect & $\begin{array}{l}\text { Allowing the client to speak without being interrupted. } \\
\text { The nurse does not judge the client. } \\
\text { The nurse makes the client feel important. } \\
\text { The nurse speaks to the client in a friendly way. } \\
\text { The nurse respects the confidentiality of information about cli- } \\
\text { ent. }\end{array}$ & $\begin{array}{l}4.6 .1 \\
4.6 .2 \\
4.6 .3 \\
4.6 .4 \\
4.11\end{array}$ \\
\hline & Participative decision making & $\begin{array}{l}\text { The nurse involves the client in deciding about the method. } \\
\text { The client understands everything told about her method. } \\
\text { The nurse helps the client achieve what she wants to with her } \\
\text { visit. } \\
\text { The nurse gives the client a chance to ask questions. } \\
\text { The client is told what to expect during a procedure. }\end{array}$ & $\begin{array}{c}4.7 \\
4.8 \\
4.9 \\
4.10 \\
5.7\end{array}$ \\
\hline
\end{tabular}




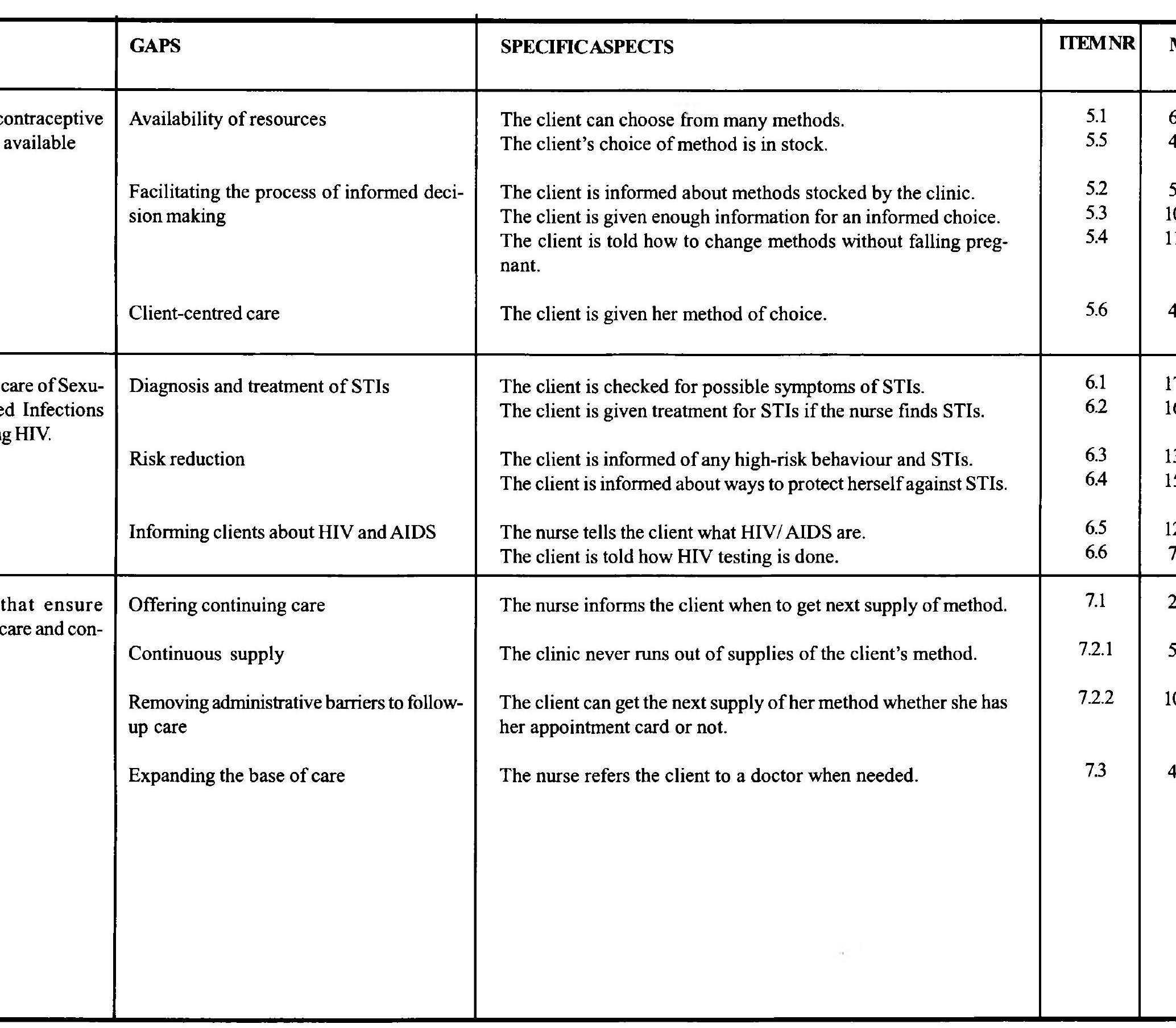


contraceptive methods should be made available to women of reproductive age through information management that focuses on correct and safe use of methods.

The Department of Health states increasing public knowledge of clients' contraceptive rights, methods and services as an objective crucial for clients to make informed choices and take control over their own well-being (DOH, 2000:21). The manager should implement measures to ensure that information management in terms of information needed for the client to make an informed method choice is implemented. Adequate information is needed for the client to make an informed choice, which is her right according the Patients' Rights Charter (DOH, 2001b:11).

\section{Guideline 4: The unit manager should promote interpersonal skills in terms of professional behaviour, consideration of cultural diversity, gaining insight in the client's situation, interpersonal respect and participative decision making when dealing with women of reproductive age.}

The Primary Health Care Package for South Africa has set treating clients with courtesy in a client-oriented way as a standard for health care delivery (DOH, 2001b:11). Good interpersonal skills used by the nurse contribute to client satisfaction (WHO, 2008:1). The nurse manager should ensure that the nurses deliver family planning services that are sensitive to the client's social circumstances (DOH,2001b:13) and demonstrate insight into the client's situation (culture sensitive as well).

\section{Guideline 5: Ensuring that the correct choice of contraceptive methods is made available to women of reproductive age through managing the availability of resources, informed decision making and client-centred care.}

In order to improve the possibility of the client having access to her method of choice, an expanded choice of contraceptives should be made available. Contraceptive policy spells out a list of methods that clients should have access to (DOH, 2000:16). The manager should always ensure the availability of resources. Methods and supplies should always be in stock. The manager should investigate and establish mechanisms for obtaining emergency supplies when needed (DOH, 2001b:13).

\section{Guideline 6: The unit manager should promote prevention and care of STIs, including HIV, amongst women of reproductive age by ensuring diagnosis and treatment of STls, risk reduction and informing clients about HIV and AIDS.}

It is considered important that clinics deliver comprehensive, integrated Primary Health Care (DOH, 2001b:12). The Department of Health urges the accelerated implementation of comprehensive plans for management of HIV and AIDS, as well as strengthening programmes in women's health $(\mathrm{DOH}$, 2004b:14). It has been stated by the United Nations that all health services should take steps to halt and reverse the spread of HIV (UN, 2008:28). The manager should ensure that all nurses are trained to assess the client's risk of contracting STIs and HIV, as well as counselling the client with regards to strategies to reduce this risk. The Department of Health urges PHC facilities to counsel clients with regards to safer sex practices, which includes promoting the acceptance and use of condoms (DOH, 2001b:25; 32).

\section{Guideline 7: The unit manager should ensure mechanisms for follow-up care and continuity of care of women of reproductive \\ age.}

Failure to provide follow-up care is considered a health care error (Muller, Bezuidenhout \& Jooste, 2006:458) which may contribute to an adverse event. The manager should remain evervigilant for administrative barriers to follow-up care and continuity of care that should be removed. The manager should establish referral mechanisms for the next level of care needed by cli- ents when their needs begin to fall outside of the scope of practice of the nurse's competence (DOH, 2001 b:32).

\section{Limitations of the study}

The research was conducted at only one clinic. The results can therefore not be generalised to other clinic settings. The results of this research are applicable to the women of reproductive age who participated in the research only. Because of the amount of time needed to complete each interview and time constraints, only fifty women of reproductive age were interviewed.

\section{Conclusion}

Family planning nurses should be encouraged to meet the expectations of service delivery of clients accessing family planning services provided by family planning clinics. This can be done by implementing the guidelines of this study. Policies to promote effective family planning services should be written by the unit manager, and nursing personnel must be made aware of the policies and where they can be located for easy reference. The policies can then be revised as more information becomes available with regards to effectively delivering family planning services to women of reproductive age.

\section{Bibliography}

ANON 2005: Wider choices. A summary of newer contraceptive alternatives for Irish women. The world of Irish nursing. June :51.

OUTON, J 2001: The practice of social research. Cape Town: Oxford University Press.

BRAAM, T (Ed). 2002: National termination of pregnancy statistics. Barometer, $7(10): 11$

BRINK, HIL 2001: Fundamentals of research methodology for health care professionals. Cape Town: Juta.

BURNS, N \& GROVE, SK 1993: The practice of nursing research. New York: WB Saunders.

BURNS, N \& GROVE, SK 1995: Understanding nursing research. Philadelphia: WB Saunders.

BURNS, N \& GROVE, SK 2005: The 
practice of nursing research. Conduct, critique and Utilization. Firth edition. Philadelphia: Elsevier Saunders.

CHAMPION, JD; SHAIN, RN \& PIPER, J 2004: Minority adolescent women with sexually transmitted diseases and a history of sexual or physical abuse. Issues in mental health. 25: 293-316.

COETZEE, D \& MOYS,A(Ed).1999: Trainers manual for the management of a person with sexually transmitted disease. Pretoria: Department of Health.

DE FREITAS, G 2007: Adolescents' knowledge of contraception in a selected area in Angola. Pretoria: University of South Africa.

DE VOS, AS 1998: Research at grass roots. A primer for the caring professions. Pretoria: Van Schaik.

DICKSON, K; ASHTON, J; PLEANER, M; MOLEKO, $\mathrm{W}$ \& MANGOTCHI, M(Editors) 2005: Going for gold, a clinic guide to the $\mathrm{Na}$ tional Adolescent Friendly Initiative, Second edition. Johannesburg: Reproductive health research unit.

DOH, 2000: National contraceptive policy guidelines within a reproductive health framework. Pretoria: Government Printers.

DOH, 2001a: Termination of pregnancy updates Department of Health: Pretoria. Available from: www.doh.gov.za, (Accessed 2 September 2004).

DOH, 2001b: The primary health care package for South Africa. A set of norms and standards. Pretoria: Government printers.

DOH, 2004a: National contraceptive service delivery guidelines: Republic of South Africa. Pretoria: Department of Health

DOH. 2004b: Strategic priorities for the national health system 2004-2009. Pretoria: Department of Health.

EGAN, G 1998: The skilled helper. A problem management approach to helping. Sixth Edition. Pacific Grove: Brooks/ Cole.
EHLERS, VJ; MAJA, T; SELLERS, E \& GOLOLO, M 2000: Adolescent mothers' utilization of reproductive health services in the Gauteng province of the Republic of South Africa. Curationis, 23(3):43-53.

EVIAN, C 2000: Primary AIDS care. Third Edition. Houghton: Jacana.

FHI 2004: Maximizing access to Quality Family Planning and Reproductive Health Services. Family Health International. Available from:

http://www.fhi.org/en/RH/Pubs/Briefs/ Factsheet5.htm, (Accessed 23 June 2006).

FLEISCHMAN, KG; HARDEE, K \& AGARWAL, K 2002: When does it makes sense to consider integrating STI and HIV services with family planning services? International family planning perspectives, 28(2): 105-112.

GUILLEBAUD, J 1994: Contraception your questions answered. Edinburgh: Churchill Livingston.

HATCHER, RA; TRUSSEL, J; STEWART, GK; KOWAL, D; GUEST, F; CATES, W \& POLICAR MS 1994: Contraceptive technology. New York: Irvington Publishers.

HATCHER, RA; RINEHART, W; BLACKBURN, R; GELLER, JS \& SHELTON, JD 2001: Essentials of contraceptive technology. Baltimore: John Hopkins University.

\section{HEALTH SYSTEMS TRUST 2002:} News. Available from:www.healthlink.org.za/news, (Accessed 25 October 2008).

\section{HEALTH SYSTEMS TRUST 2007:}

Health Statistics. Available from:www.healthlink.org.za/ healthstats, (Accessed 25 October 2008).

HELLERSTEDT, WL\& RADEL, EE 2004: Sexual activity and sexual health of adolescents. IJCE, 20(2): 29-32.

JARVIS, S 2005: Long-acting reversible contraception: new guidelines form NICE. Nurse prescribing. 3(6): 253-256.

JHPIEGO, 1998(a): Family planning programs: Benefits of good quality.
Population reports, Series Journal, 37(1)1-4. Available from: (www.info forhealth.org/pr/j47/ j47chap1_2.shtml, (Accessed 2 July 2007).

KIRBY, S 2006: YFS business plan. Sandton: LoveLife.

KOLS, AJ \& SHERMAN, JE 1998: Family planning programmes: Improving quality. Population reports. 26(3): November 1998.

KRUGER, WM \& STEYN, PS 2006: Contraception for first-time users: a problem-orientated guide to product selection and safe prescription. Professional nursing today. 10(3): 12-18.

LESTER, C \& ALLAN,A. 2005: Teenage sexual health needs: asking the consumers. Health Education. 106(4):315-328.

LETE, I 2006: How to prescribe....s? The European Journal of contraception and reproductive health care. pp. 1326.

MEDICAL RESEARCH COUNCIL 2001: Contraceptive prevalence rate. Available from: www.gov.za/facts, (Accessed on 2 September 2004).

METCALF, T 2004: Sexual health: meeting adolescents' needs. Nursing standard. 18(46): 40-43.

MULLER, M; BEZUIDENHOUT,MC \& JOOSTE, K 2006: Health care services management. Kenwyn: Juta.

PARAHOO, K 1997: Nursing Research. Houndsmills. Macmillan Press.

POWLSON, M(Ed) 2004: Medical and Service Delivery Guidelines for Family Planning. Third edition. London: IPPF medical publications, $435 \mathrm{p}$.

PRAXIOM 2008: ISO 90012008 Gap analysis tool. Available from: http:// www.praxiom.com/iso-gap.htm, (Accessed 1 October 2008).

RAMCHANDRAN, D 2007: Developing a continuing client strategy, Population reports. Series J, No 55, Baltimore, John Hopkins Bloomberg School of public health, March 2007. 
RHRU, 2000a: Sexual and Reproductive Heath Services. Facilitators guide, Johannesburg: Wits University.

RHRU, 2000b. Sexual and Reproductive Health course, module1 Framework for the provision of Sexual and Reproductive Heath Services. Facilitators guide, Johannesburg: Wits University.

RUDY, S; TABBUTT-HENRY, J; SCHAEFER, \& MCQUADE, P 2003: Improving client-provider interaction. Population reports, Series Q, (1): 4-6.

SOANES, C; SPOONER, A; HAWKER, S. (Editors). 2001: Oxford dictionary, thesaurus and wordpower guide. Cape Town: Oxford University Press.

SMIT, PJ \& CRONJE J de J 2002: Management principles. A contemporary edition for Africa. Second edition. Landsdowne: Juta.

TECHTARGET 2007: What is a gap analysis? Available from:http:// searchio-midmarket.techtarget.com/ sDefinition0,,sid83 gci831294,00.html, (Accessed 1 October 2008).

UNIVERSTTY OFSASKATCHEWAN 2008: Definition of Primary Health Care. Available from: www.medicine.uask.cal research/health-research/primaryhealth-care, (Accessed on 19 September 2008).

UNITED NATIONS, 2008: The millennium development goals report. New York: United Nations.

VENUGOPAL, ST \& UPADHYAY,UD 2002: Birth spacing - three to five saves lives. Population reports, 30(3): 1-23.

WHO. 2000a: Improving the quality of family planning service delivery. Available fromhttp:/www.who.int/reproductive-health/familyplanning/ delivery.html, (Accessed 2 September 2004).

WHO, 2000b: Safe motherhood newsletter, 28(1):6.

WHO 2003: Family planning. Improving the quality of family planning service delivery. Department of Reproductive Health and Research, Word Health
Organization. lp. Available from: www.who.int/reproductive-health/ familyplanning/delivery/html, (Accessed 2 September 2006).

WHO 2005: Integrating STI/RHI care for reproductive health Sexually Transmitted and other Reproductive Tract Infections a guide to essential practice, Geneva: World Health Organization.

WHO 2008: Selected practice recommendations for contraceptive use. Available from:www.who.int/ rhs_02_07/rhr_02_07_8.html, (Accessed on 30 June 2006). 